\title{
Flattening of the resonance spectrum of hadrons from $\kappa$-deformed Poincaré algebra
}

\author{
Jishnu Dey*, Paulo Leal Ferreira, Lauro Tomio \\ Instituto de Fisica Teórica \\ Universidade Estadual Paulista \\ Rua Pamplona 145 \\ 01405-900 - São Paulo, S.P. \\ Brazil \\ and \\ Rajkumar Roy Choudhury \\ Indian Statistical Institute \\ 203 B. T. Road \\ Calcutta 700035 \\ India
}

"Supported by FAPESP, S.P., Brazil and in part by DST grant no. SP/S2/04/93, Govt. of India, permanent address : 1/10 Prince Golam Md. Road, Calcutta 700026 , India. 

Instituto de Física Teórica

Universidade Estadual Paulista

Rua Pamplona, 145

01405-900 - São Paulo, S.P.

Brazil

Telephone: 55 (11) 251-5155

Telefax: 55 (11) 288-8224

Telex: 55 (11) 31870 UJMFBR

Electronic Address: LIBRARY@IFT.UESP.ANSP.BR 47553::LIBRARY 


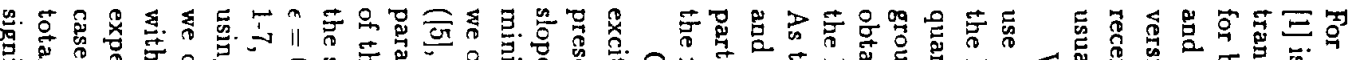

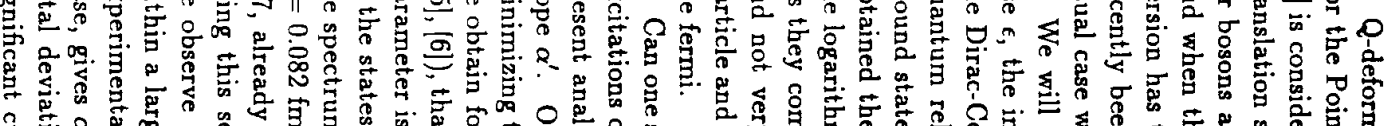

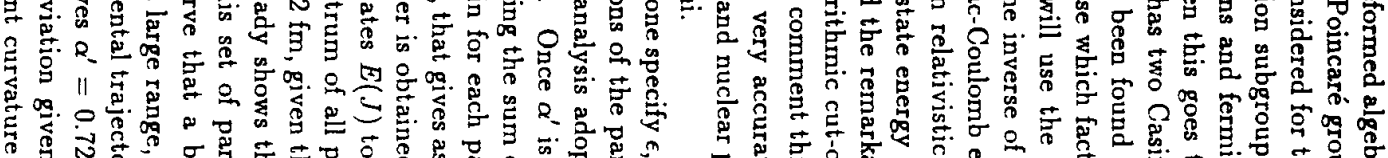

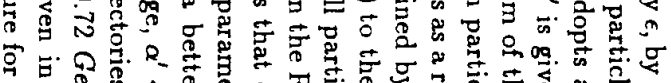

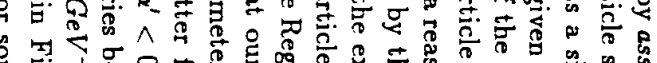

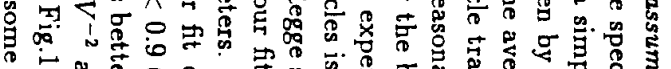

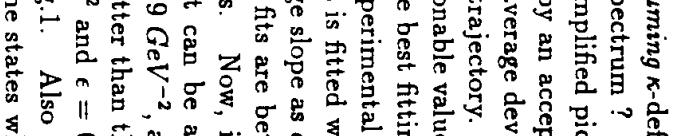

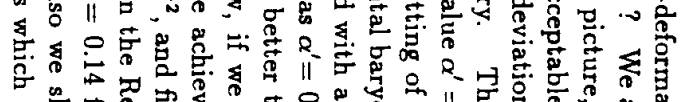

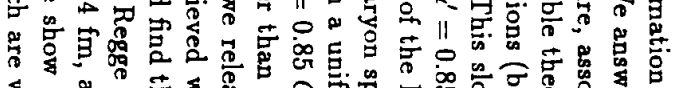

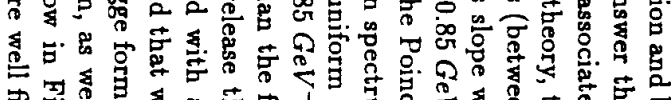

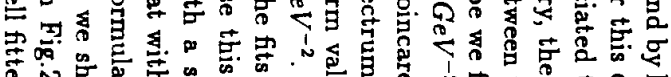

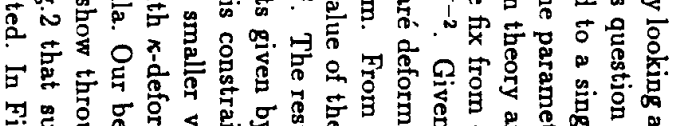

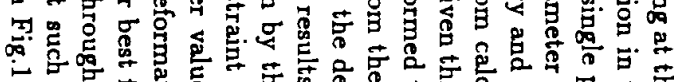

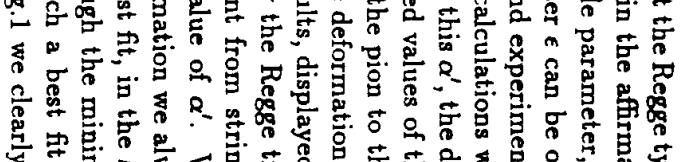

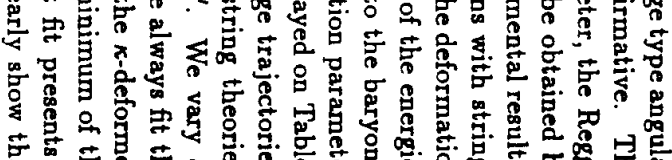

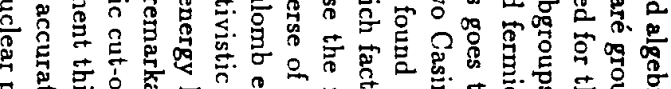

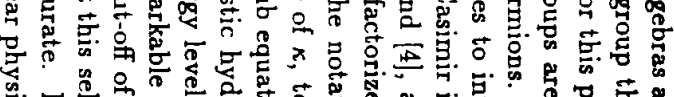

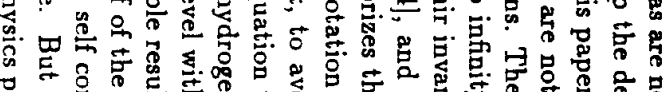

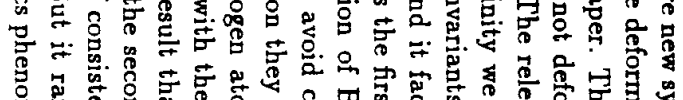

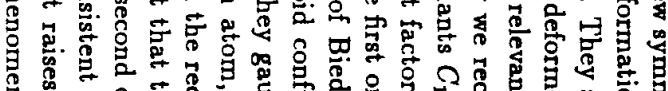

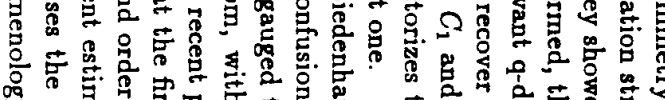

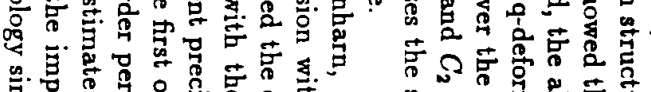

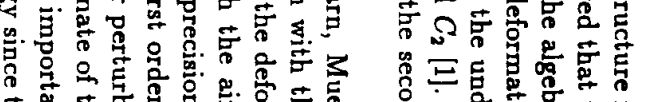

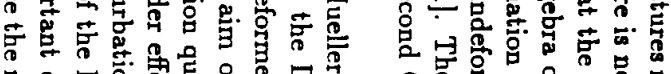

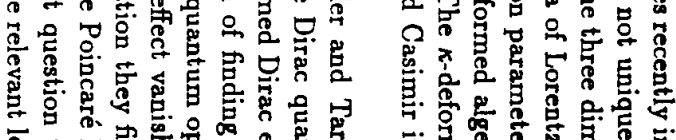

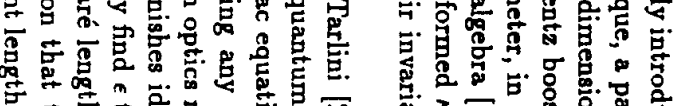

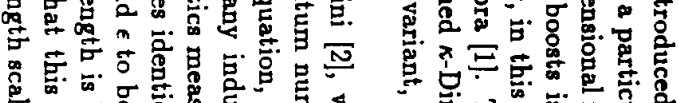

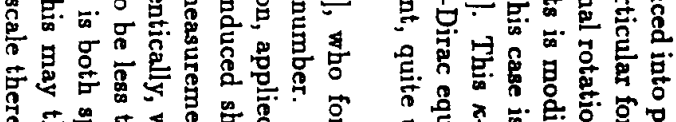

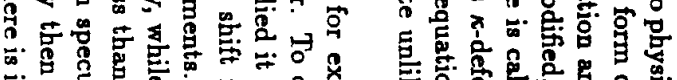

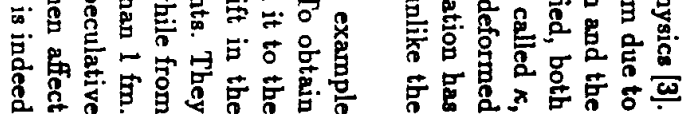



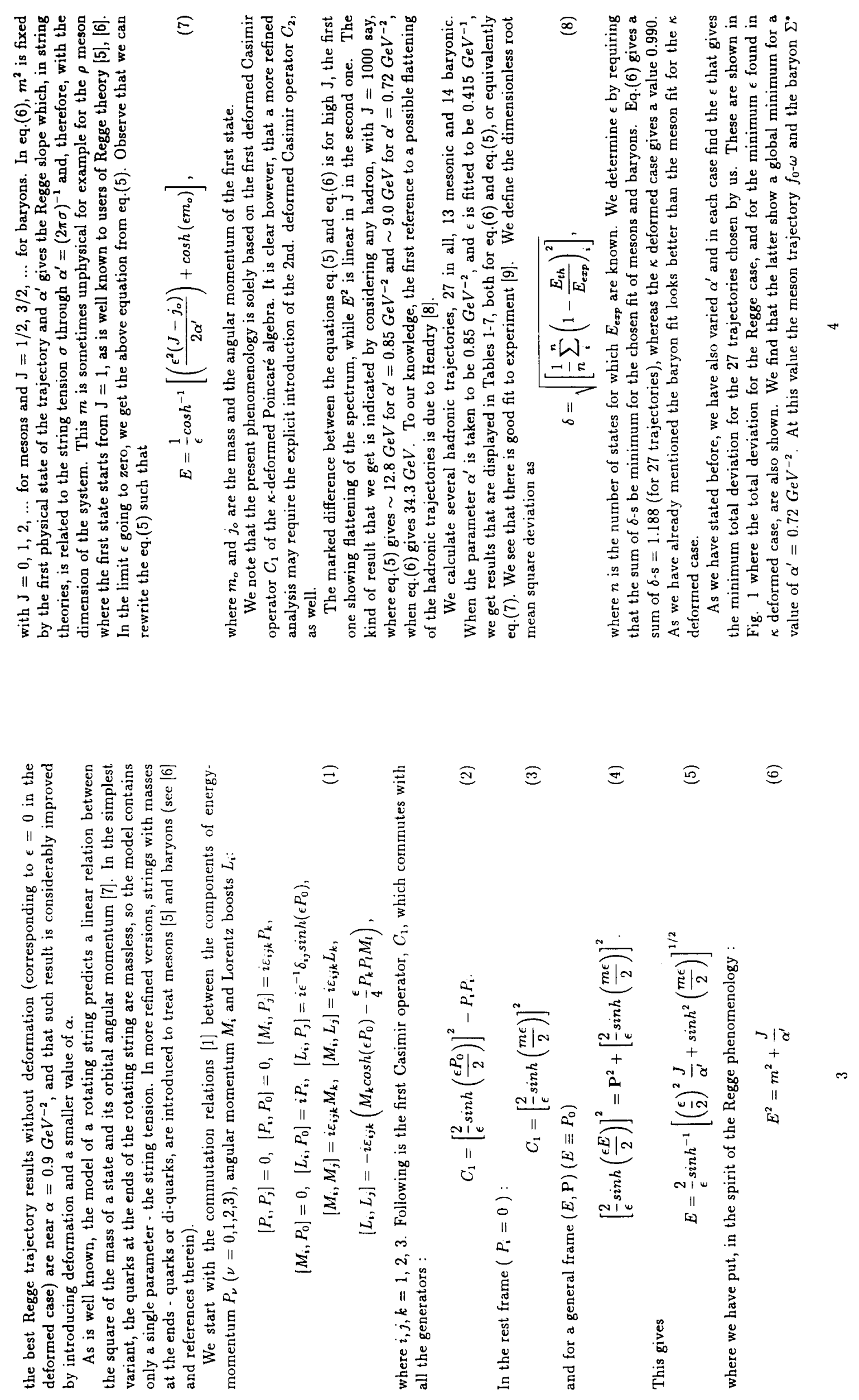


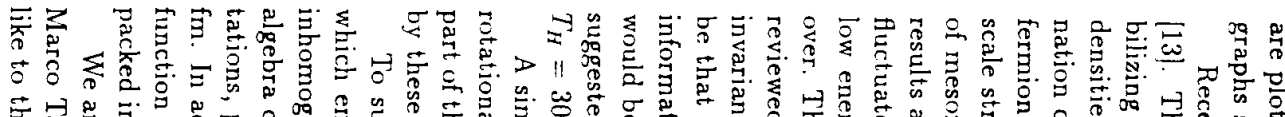

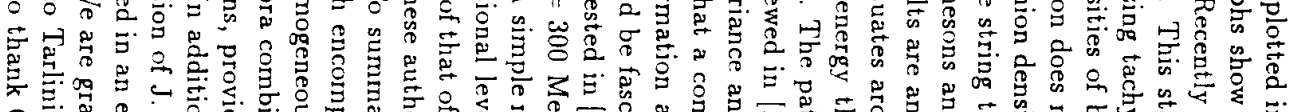

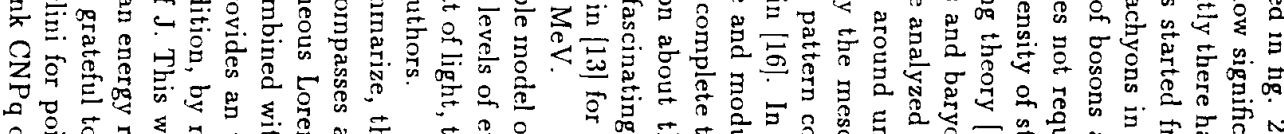

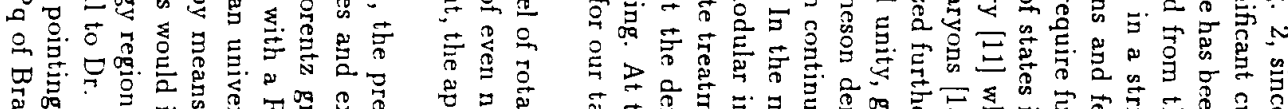

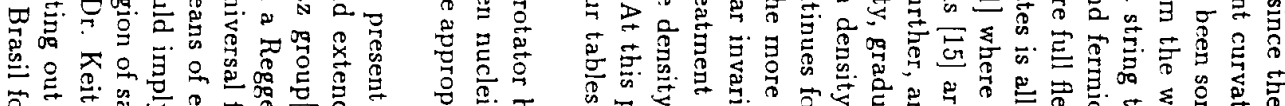

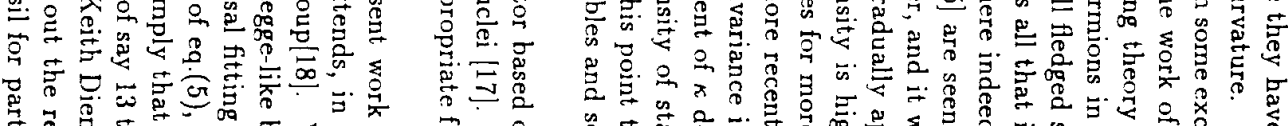

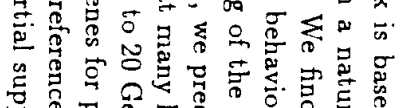

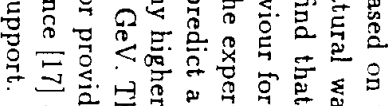

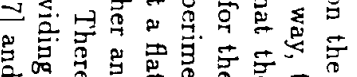

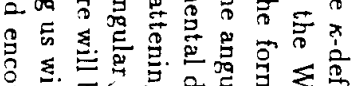

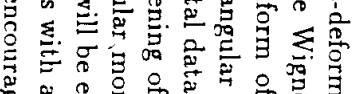

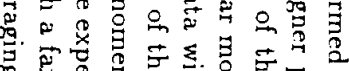

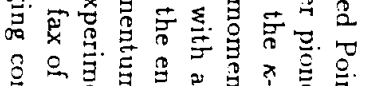

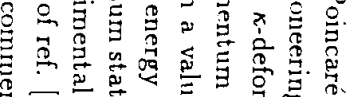

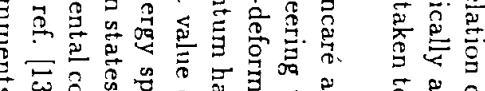

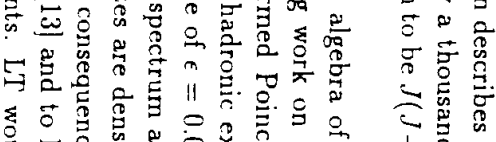

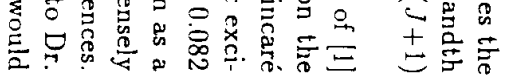
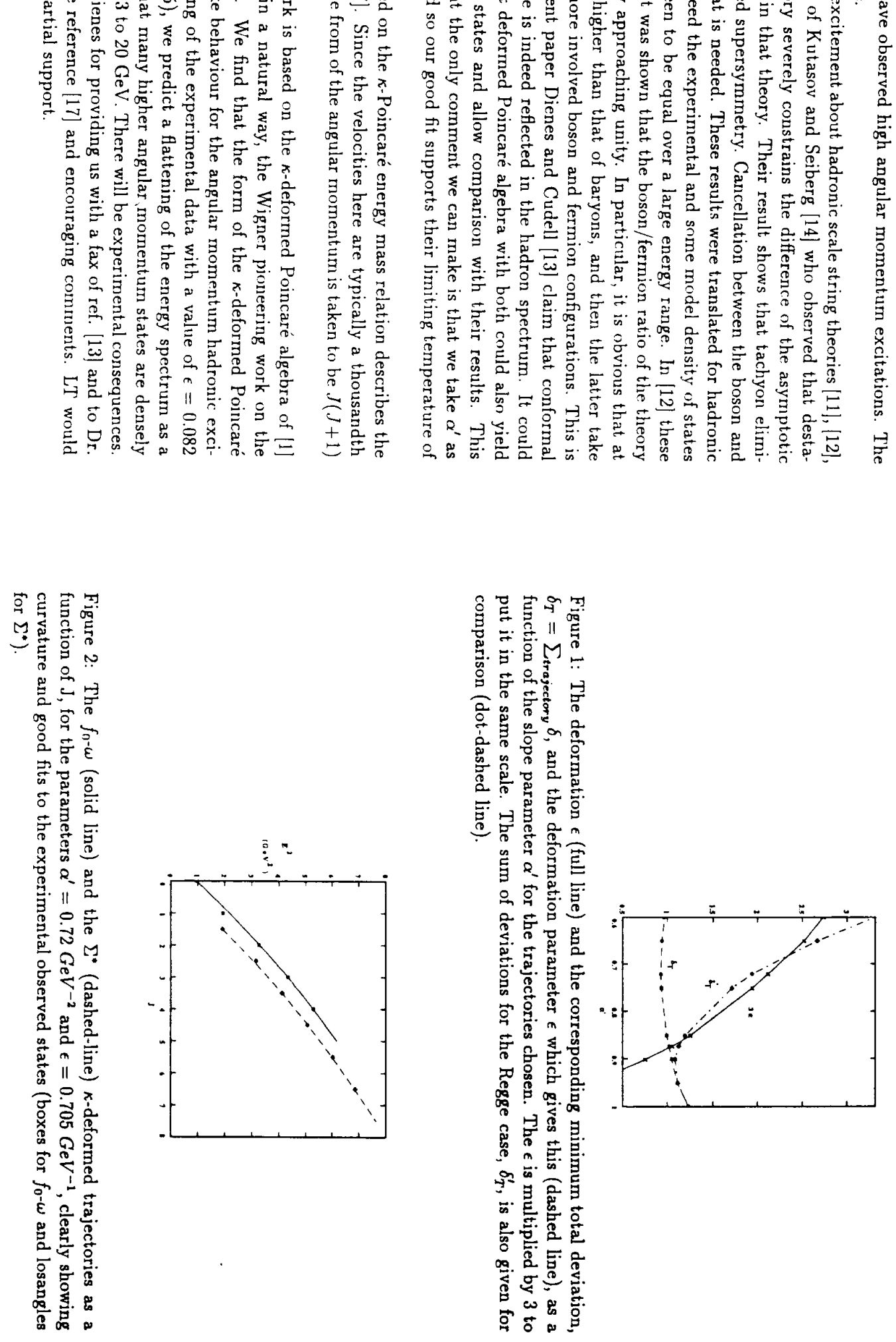

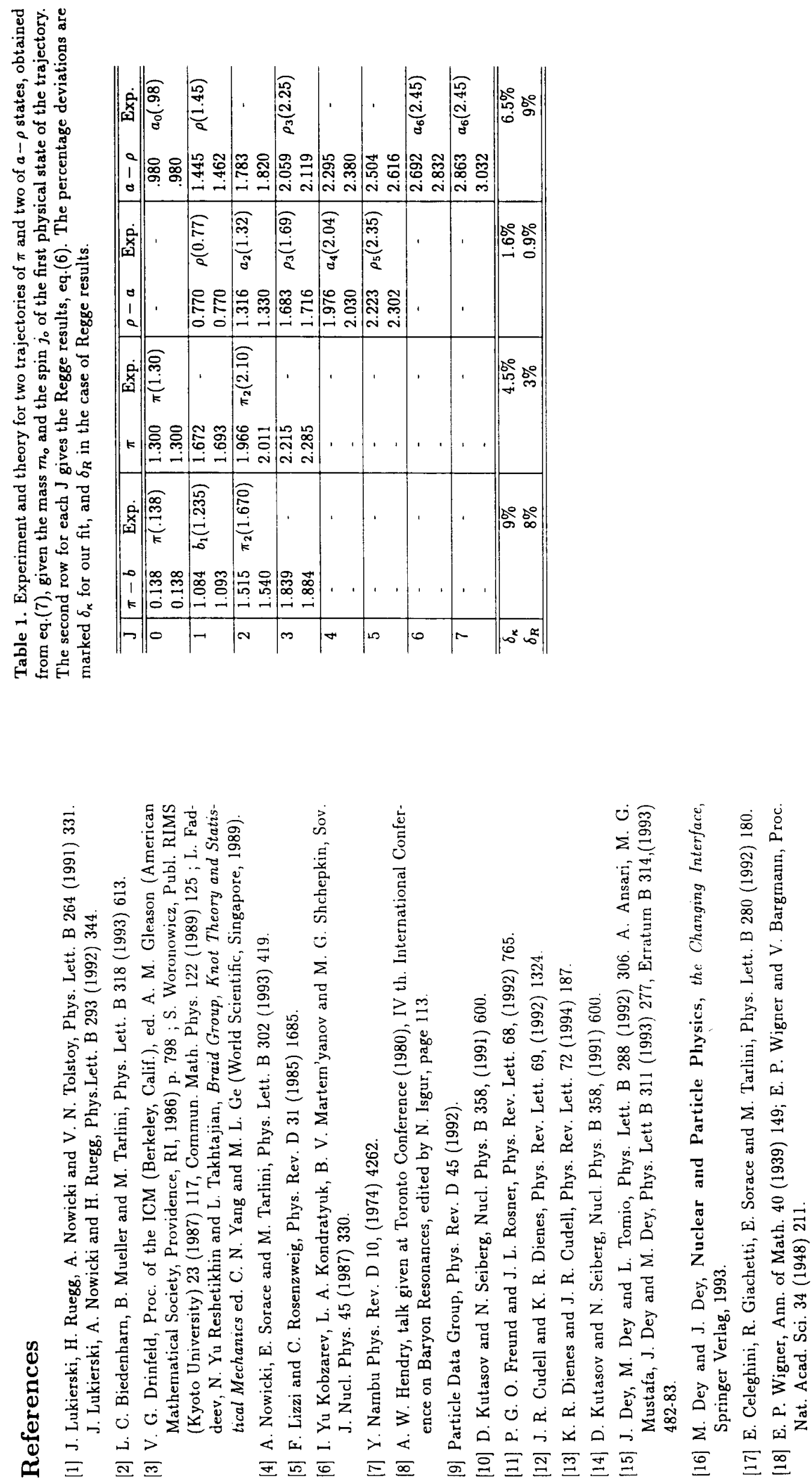


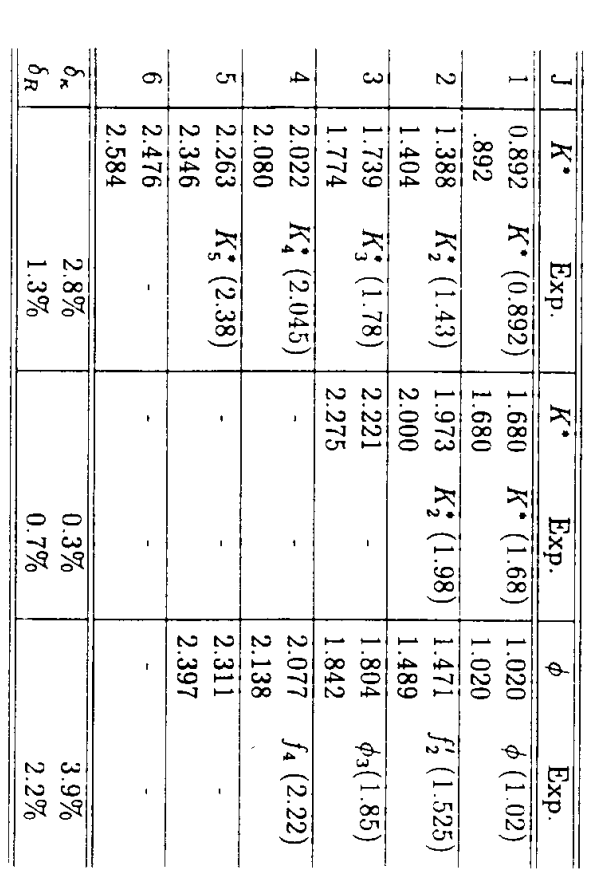

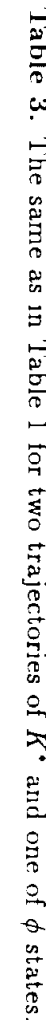

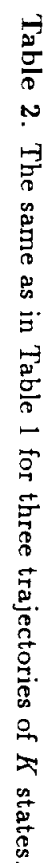

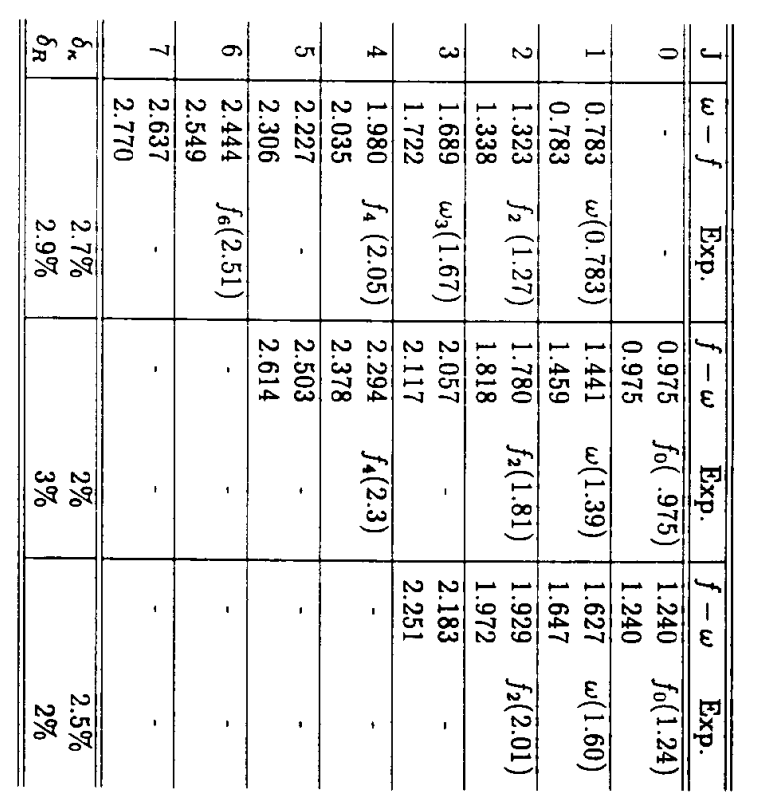




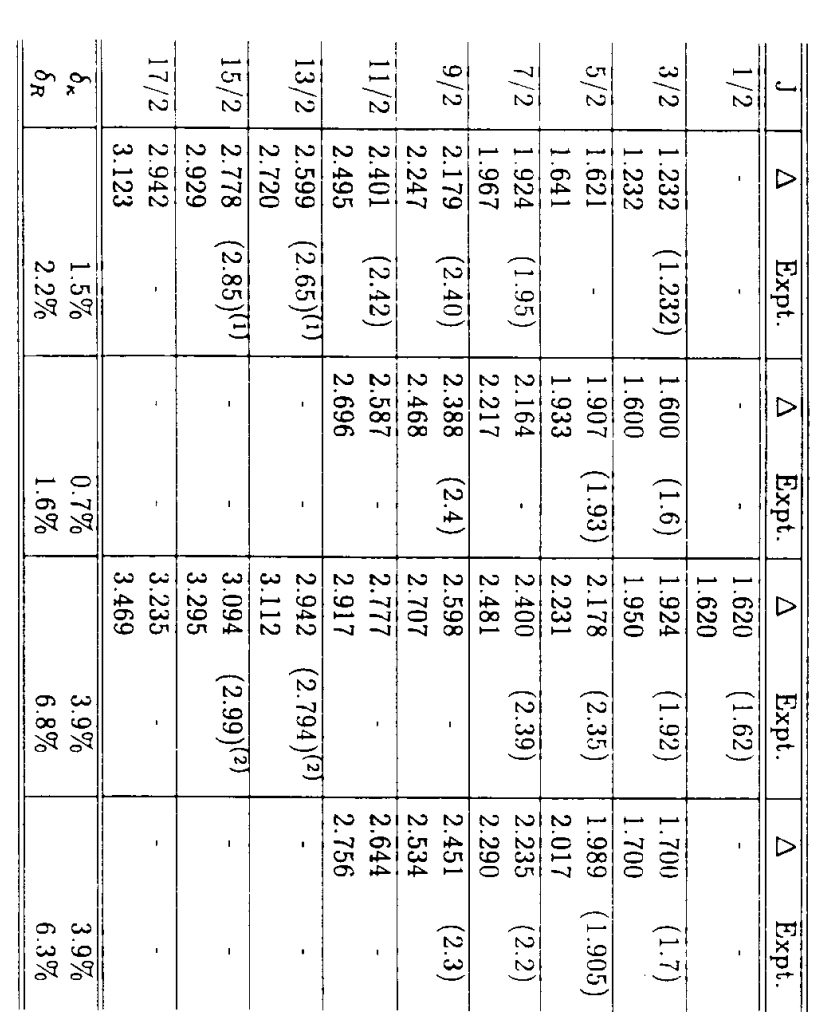

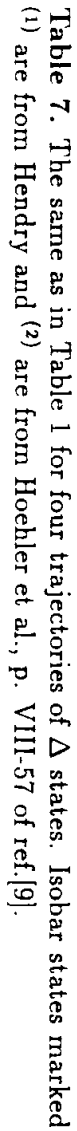

